\title{
HETEROGENEOUS SOLAR PHOTO-FENTON DEGRADATION OF REACTIVE BLACK 5 USING FOUNDRY SAND AND FLY ASH: VALUE ADDITION TO WASTE
}

\author{
Himadri RAJPUT ${ }^{\mathrm{a}}$, Anoop VERMA ${ }^{\mathrm{a}}$, Manpreet KAUR ${ }^{\mathrm{a}}$, Taranjeet KAUR ${ }^{\mathrm{b}}$, Amrit Pal TOOR \\ ${ }^{a}$ School of Energy and Environment, Thapar University, Thapar Technology Campus, Patiala 147004, India \\ ${ }^{b}$ Dr. S. S. Bhatnagar University Institute of Chemical Engineering and Technology, \\ Panjab University, Sector 14, Chandigarh 160014, India \\ Submitted 08 May 2015; accepted 14 Oct. 2015
}

\begin{abstract}
This work evaluates the scope of alternative sources of iron i.e. Foundry Sand (FS), Fly Ash (FA) and mixture of FS and FA in heterogeneous photo-Fenton process for the degradation and decolourization of the dye Reactive Black5 (RB5). SEM-EDS characterization of FS and FA confirmed the presence of iron and aluminium which are required for photo-Fenton. In case of FS as an iron source, results confirmed the degradation and decolourization efficiency of $90 \%$ in $70 \mathrm{~min}$ and $45 \mathrm{~min}$ respectively when the reaction parameters were $\mathrm{H}_{2} \mathrm{O}_{2}=2.2 \mathrm{mM}$, FS dose = $0.5 \mathrm{~g}$, pH 3. With FA $90 \%$ degradation was achieved within $30 \mathrm{~min}$ and $93 \%$ decolourization rate within $15 \mathrm{~min}$. When a mixture of FS $(0.1 \mathrm{gm})$ and FA $(0.05 \mathrm{gm})$ is used as source of iron $99 \%$ degradation and decolourization of the dye was achieved under the reaction conditions where $\mathrm{H}_{2} \mathrm{O}_{2}=2.2 \mathrm{mM}$, FA:FS $=1: 2, \mathrm{pH} 3$.
\end{abstract}

Keywords: foundry sand; fly ash; dye Reactive Black 5; photo-Fenton; degradation; decolourization.

\section{Introduction}

Dye effluents from textile industries are significant sources of environmental pollution as it is among one of the most water demanding sectors (Chaco et al. 2006; Wang et al. 2008). This water consumption, allied to high dosage of dyes, originates extremely colorized effluents. Release of these wastewaters to natural environment is described as very problematic to aquatic life as transmission of light, photosynthesis and aquatic life diversity will be affected and is also mutagenic to humans (Chung et al. 1992; Chung, Stevens 1993). The dyes do not bind to the fabric completely and its loss in wastewaters depending on the class of the dye can vary from $2 \%$ for the basic dyes to $50 \%$ for the reactive dyes, causing serious environmental problems (Park, Choi 2003; Mass, Chaudhari 2005; Pandey et al. 2007). They have high solubility and stability, stability, due to which are widely used in many applications (Mahmoodi, Arami 2009). Reactive Black 5 (RB5) is one of the oldest reactive dyes, which is consumed very heavily in textile industries worldwide for the dying of woollen, cotton and nylon fabrics (Arslan et al. 1999). It is reported to be toxic and can cause allergic reactions of the respiratory tract (Lars, Mallika 1997).
A variety of physical and chemical processes, such as elimination by adsorption on activated carbon, ozone oxidation, coagulation by a chemical agent, electrochemical method, hypochlorite oxidation etc. are available for the treatment of dye waste effluents (Yoshida et al. 1999; Tanaka et al. 2000). Nevertheless, these methods are usually inefficient, costly, non-destructive and resulted in the production of secondary waste products (Sun et al. 2008). On the other hand, biological treatment usually takes long time besides producing a large quantity of sludge.

Advanced oxidation technologies (AOTs) are innovative methods and are extremely useful where substances are resistant to conventional treatment technologies. AOTs are oxidation processes, where hydroxyl radicals $(\cdot \mathrm{OH})$ generates that are very effective in degrading organic pollutants due to their strong oxidant power and non selective species (Toor et al. 2006). Among these AOTs, Fenton's reagent is particularly gained attention because of its low cost, the lack of toxicity of the reagents, and absence of a mass transfer limitation due to its simplicity of the technology and homogeneous catalytic nature (Liao et al. 2009). However, it should be pointed out that the homogeneous Fenton process has significant disadvantage of 
sludge-containing Fe ion at the end of the wastewater and its removal/treatment is very expensive and needs large amount of chemicals and manpower.

Various waste materials of different kinds have been tested as an iron source in heterogeneous photo-Fenton degradation (Lucking et al. 1998; Chaudhuri, Sur 2000; Mecozzi et al. 2006). Photo-Fenton activity in each of the above case can be related to the activation of hydrogen peroxide $\left(\mathrm{H}_{2} \mathrm{O}_{2}\right)$ by the ions of iron leached from the waste materials into the solution. Iron ions release is slow in the case of heterogeneous photo-Fenton reactions, which limits undesired reaction in comparison with the conventional homogenous catalysis.

To overcome the disadvantages of the homogeneous Fenton process, and also considering the possibility of recovering catalyst, attempt has been made to use foundry sand (FS) and fly ash (FA) as an alternative iron source. The key motivating factor for using FS and FA is to identify its iron leaching potential for photo-Fenton studies along with reuse opportunities. Thus, the study proposes alternatives to landfill disposal and ultimately cost saving for materials that can be reused beneficially.

In this context, the present study investigates the degradation of RB5 using FS, FA and their mixture as a new low-cost iron source for the heterogeneous photo-Fenton process. To the best of our knowledge, this is the first reported study towards the use of foundry sand and fly ash as a heterogeneous catalyst in photo-Fenton degradation of dyes. This would be of economic interest keeping in mind the high costs required for disposal of FS and FA which we are using as a catalyst that is commonly considered as a waste.

\section{Experimental}

\subsection{Reagents and chemicals}

Reactive Black 5 (RB5), technical grade (55\%), was purchased from Sigma- Aldrich and used as such without any further purification. Waste FS was received from Munjal Industries, Gurgoan (India) and FA was received from thermal plant, Ropar, Punjab (India) as a gift sample and used as received without any further modifications. $\mathrm{H}_{2} \mathrm{O}_{2}$ $(30 \% \mathrm{w} / \mathrm{v})$ was obtained from SD Fine Chemicals Limited, India. The $\mathrm{pH}$ of the solution was adjusted using $0.1 \mathrm{~N} \mathrm{H}_{2} \mathrm{SO}_{4}$. Throughout the study, all the chemicals were of analytical grade and used as such without any further purification. For experimental study, $100 \mathrm{mgL}^{-1} \mathrm{RB} 5$ solution was prepared and double distilled water was used for the preparation of all solutions.

\subsection{Photoreactor and experimental procedure}

The shallow pond batch slurry reactor used in this study (Fig. 1) was made up of borosil glass, $160 \mathrm{~mm}$ in diameter and $52 \mathrm{~mm}$ in height having a capacity of $1200 \mathrm{~mL}$.
For heterogeneous solar photo-Fenton studies, $200 \mathrm{ml}$ of RB5 solution (100 $\left.\mathrm{mgL}^{-1}\right)$ was taken in this batch reactor at $\mathrm{pH} 3$ and known amount of Fenton reagent $\left(\mathrm{FS}+\mathrm{H}_{2} \mathrm{O}_{2}\right)$, $\left(\mathrm{FA}+\mathrm{H}_{2} \mathrm{O}_{2}\right)$ and $\left(\mathrm{FS}+\mathrm{FA}+\mathrm{H}_{2} \mathrm{O}_{2}\right)$ were added. The suspensions were kept in dark under stirring for $30 \mathrm{~min}$ for attaining any adsorption-desorption equilibrium between FS, FA and dye. For photo-Fenton studies, the above samples were kept in sunlight under same conditions of stirring and aeration. Samples were taken after regular intervals of time, filtered and analyzed for decolourization and degradation studies using an UV-visible spectrophotometer.

All the reported solar experiments were carried during timings 11.00 a.m. - 3.00 p.m. in months of MarchMay, 2014 at Patiala, Punjab. To check the reproducibility of results, experiments were repeated thrice and average values are reported with standard deviation varying from $1-3 \%$.

\subsection{Analytical analysis}

The decolourization and degradation studies were performed with UV- visible (Hitachi V- 500 UV/VIS (Japan)) double- beam spectrophotometer with RB5 at $310 \mathrm{~nm}$ and $595 \mathrm{~nm}$.

For the characterization of FS and FA, scanning electron microscope (SEM) and energy-dispersive X-ray spectroscopy (EDS) was performed as shown in Figure 2(a) and (b), Figure 3(a) and 3(b) respectively. Chemical composition of foundry sand and fly ash is reported in Table 1 and Table 2 (with accuracy of $\pm 0.5-1.0 \%$ ). The analysis indicated the absence of any heavy metal in FS and FA, thus eliminated any risk of their leaching. A considerable amount of iron (23.16\%) in FS and aluminium (17.66\%) in FA was reported which could be utilized in photoFenton process. Although amount of iron detected in FA was less as compared to FS, but the presence of considerable amount of aluminium confirmed its participation in photo-Fenton reactions which could be used in the place of iron.

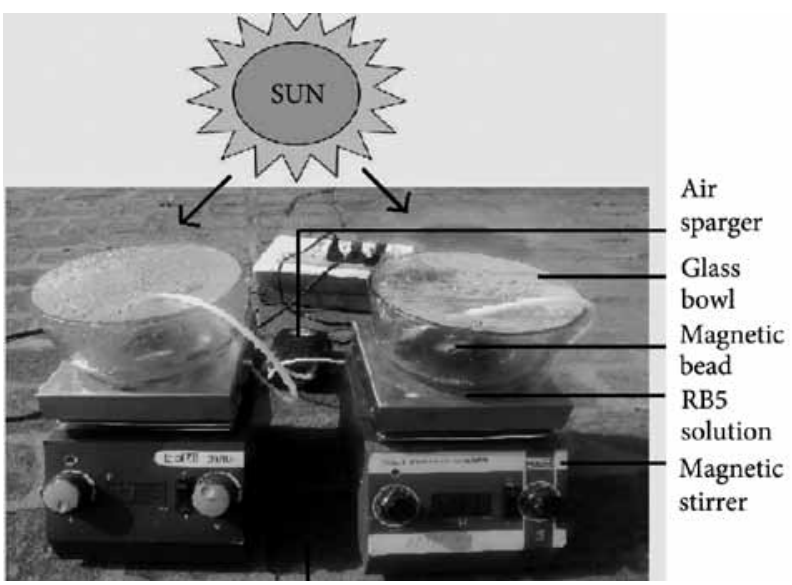

Fig. 1. Shallow pond slurry batch reactor 


\section{Results and discussion}

\subsection{Photo-Fenton studies using foundry sand as an iron source}

\subsubsection{Preliminary experiments}

Preliminary experiments were performed to assess the catalytic activity of FS as a catalyst and the effect of individual parameter in the degradation of RB5 by heterogeneous photo-Fenton process. Low and negligible degradation and decolourization (less than 20\%) in $120 \mathrm{~min}$ was achieved in the presence of $\mathrm{H}_{2} \mathrm{O}_{2}$ only, FS only and sunlight only as shown in Figure 4(a) and 4(b). This could be ascribed to limited production of $\mathrm{OH}$ radicals due to the insufficient availability of the resources in all three above cases required for the photo-Fenton process. In Fenton process $\left(\mathrm{H}_{2} \mathrm{O}_{2}+\mathrm{FS}\right), 35 \%$ degradation in $90 \mathrm{~min}$ and $50 \%$ decolourization rates in 60 min were achieved. It is worth noting that $75 \%$ degradation in $90 \mathrm{~min}$ and decolourization efficiency of $85 \%$ in $60 \mathrm{~min}$ was achieved in the presence of FS as a heterogeneous catalyst, $\mathrm{H}_{2} \mathrm{O}_{2}$ and sunlight. The photo-Fenton results indicated that catalyst reacts with $\mathrm{H}_{2} \mathrm{O}_{2}$ in the presence of photons to generate $\mathrm{OH}$ radicals for the degradation of $\mathrm{RB} 5$. In the present work, generation of $\mathrm{OH}$ radicals for degradation of RB5 was proposed via photo-Fenton mechanism using FS and $\mathrm{FA}$ as an iron source.

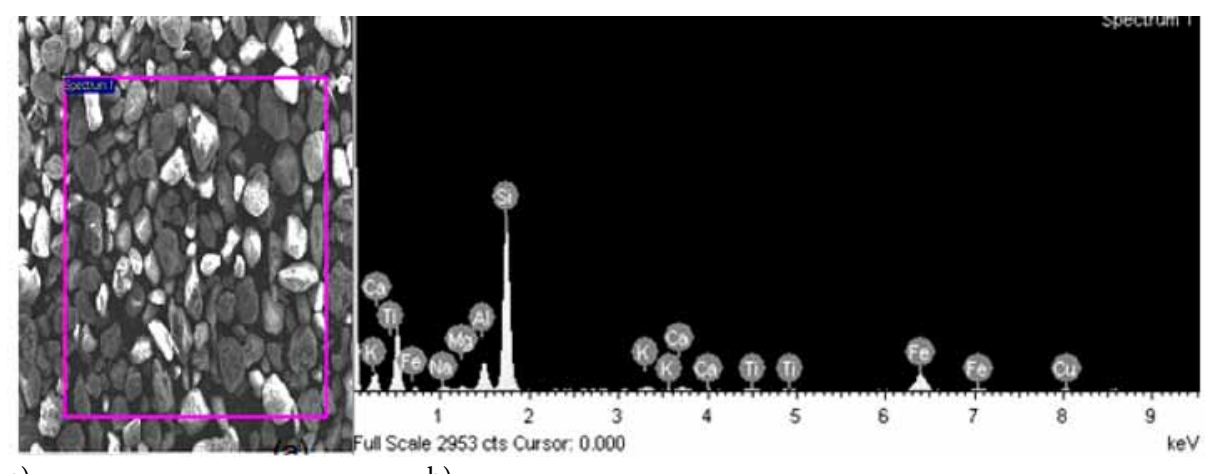

a)

b)

Fig. 2. a) SEM micrograph, b) EDS pattern of FS

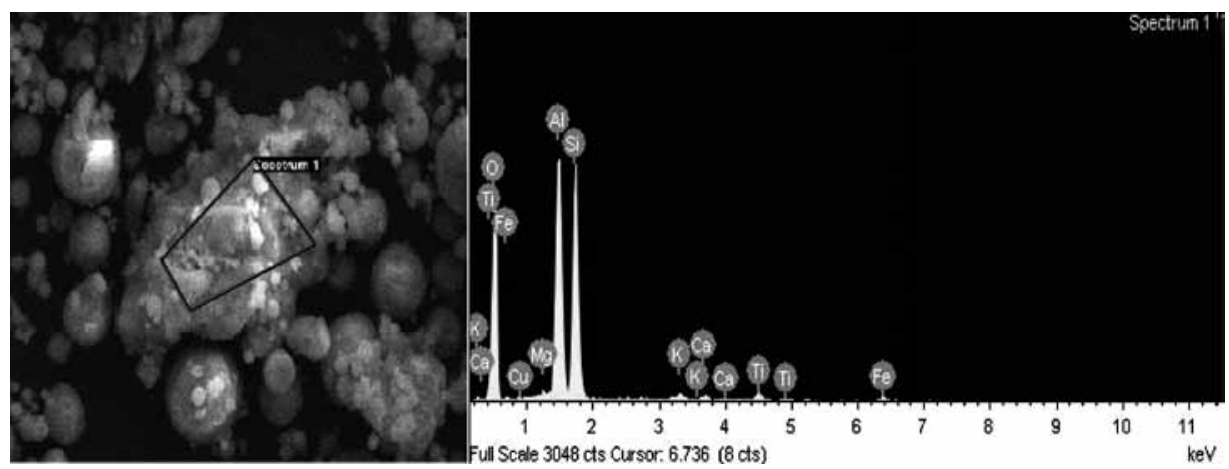

a)

b)

Fig. 3. a) SEM micrograph, b) EDS pattern of FA

Table 1. Composition of FS

\begin{tabular}{rcccccccccc}
\hline Element & $\mathrm{Na} \mathrm{K}$ & $\mathrm{Mg} \mathrm{K}$ & $\mathrm{Al} \mathrm{K}$ & $\mathrm{Si} \mathrm{K}$ & $\mathrm{K} \mathrm{K}$ & $\mathrm{Ca} \mathrm{K}$ & $\mathrm{Ti} \mathrm{K}$ & $\mathrm{Fe} \mathrm{K}$ & $\mathrm{Cu} \mathrm{K}$ & Total \\
\hline Weight \% & 1.93 & 1.21 & 7.85 & 58.10 & 1.77 & 1.49 & 1.36 & 23.16 & 3.13 & 100 \\
Atomic \% & 2.73 & 1.62 & 9.48 & 67.43 & 1.48 & 1.21 & 0.93 & 13.52 & 1.60 & \\
\hline
\end{tabular}

Table 2. Composition of fly ash

\begin{tabular}{rcccccccccc}
\hline Element & $\mathrm{O} \mathrm{K}$ & $\mathrm{Mg} \mathrm{K}$ & $\mathrm{Al} \mathrm{K}$ & $\mathrm{Si} \mathrm{K}$ & $\mathrm{K} \mathrm{K}$ & $\mathrm{Ca} \mathrm{K}$ & $\mathrm{Ti} \mathrm{K}$ & $\mathrm{Fe} \mathrm{K}$ & $\mathrm{Cu} \mathrm{K}$ & Total \\
\hline Weight \% & 55.87 & 0.42 & 17.66 & 21.85 & 0.67 & 0.50 & 1.33 & 1.00 & 0.70 & 100 \\
Atomic \% & 69.45 & 0.35 & 13.02 & 15.47 & 0.34 & 0.25 & 0.55 & 0.35 & 0.22 & \\
\hline
\end{tabular}




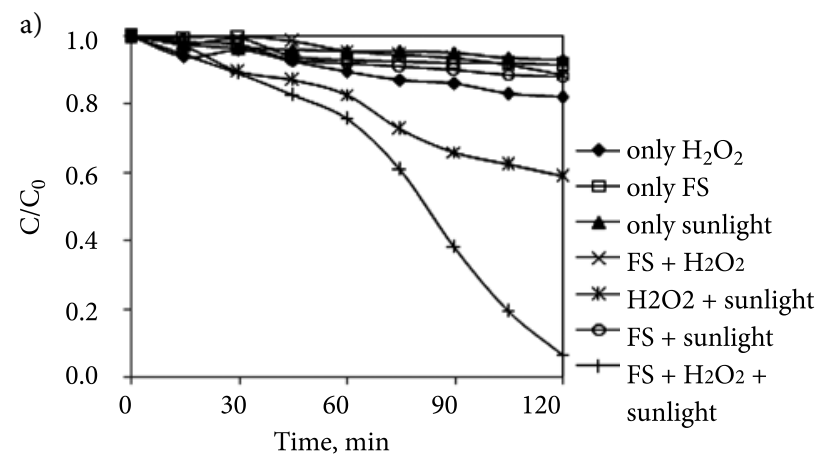

b)

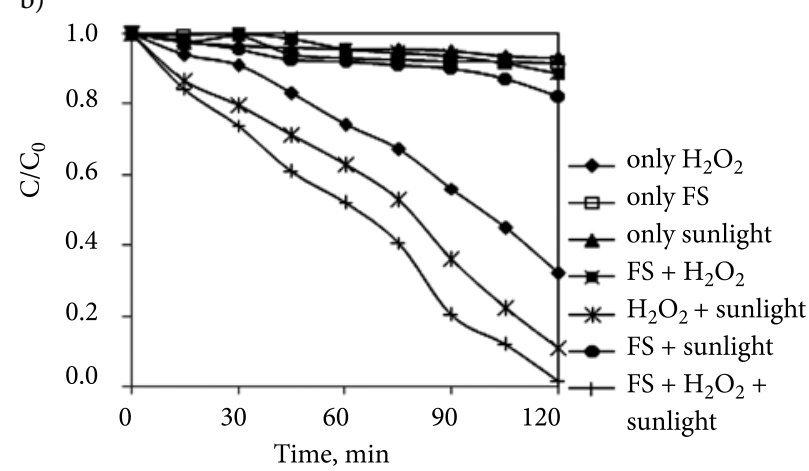

Fig. 4. Preliminary experiments performed under different conditions to evaluate their efficiency towards a) degradation and $b$ ) decolourization of RB5 using FS (where,

$\mathrm{C}=$ concentration of dye at time $t$ and $\mathrm{C}_{0}=$ initial concentration of dye)

a)

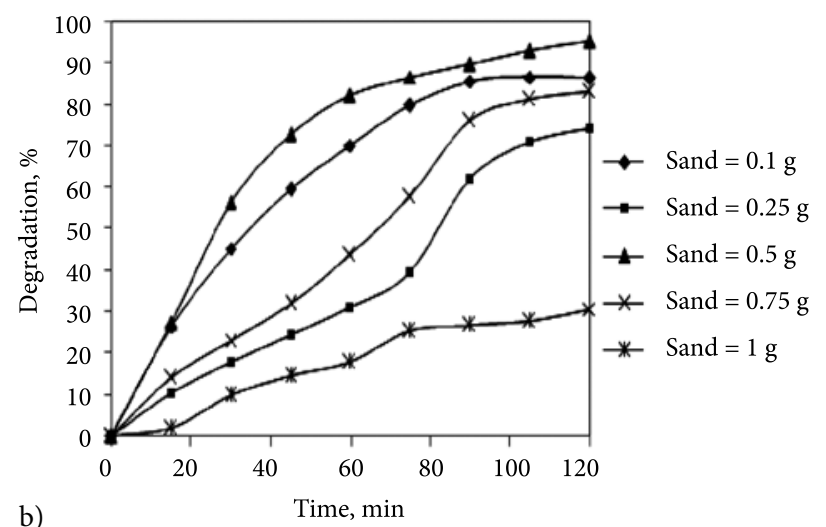

b)

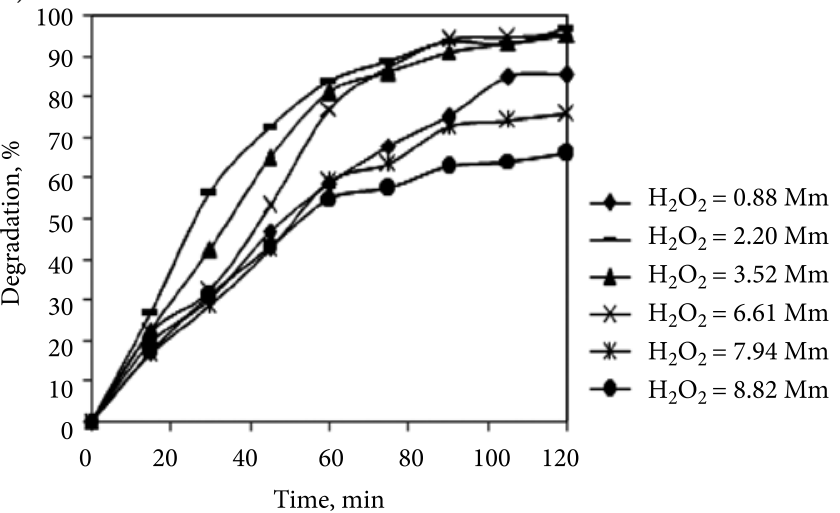

\subsubsection{Effect of variation of FS}

FS was used as an iron source in varying concentrations ranging from $0.1-1.0 \mathrm{gm}$ during the photo-Fenton treatment process while maintaining the other parameters constant. The results indicated that initial increase of FS till $0.5 \mathrm{gm}$ increases degradation and decolourization of the dye as shown in Figure 5(a). The lower degradation capacity of FS at small concentrations was probably due to the low $\mathrm{OH}$ radical production and their availability for oxidation. Further increase of FS dosage from 0.5 gm-1.0 gm, degradation and decolourization of dye decreased. This reduction can be explained by $\mathrm{OH}$ radicals scavenging either by the reaction with hydrogen peroxide or by the reaction with $\mathrm{Fe}^{+2}$ as expressed in the equations (Djeffal et al. 2013):

$$
\begin{gathered}
\mathrm{H}_{2} \mathrm{O}_{2}+\mathrm{OH}^{\cdot} \rightarrow \mathrm{H}_{2} \mathrm{O}+\mathrm{OH}_{2}^{\cdot} \\
\mathrm{Fe}^{+2}+\mathrm{OH}^{\cdot} \rightarrow \mathrm{OH}^{\cdot}+\mathrm{Fe}^{+3}
\end{gathered}
$$

The effective degradation (90\%) within 90 min and decolourization (90\%) within 60 min was achieved at 0.5 gm FS dosage.

\subsubsection{Effect of $\mathrm{H}_{2} \mathrm{O}_{2}$ concentration}

Figure 5(b) shows the degradation and decolourization of $\mathrm{RB} 5$ at different dosage of $\mathrm{H}_{2} \mathrm{O}_{2}$. To optimize the dosage, $\mathrm{H}_{2} \mathrm{O}_{2}$ was varied from $0.0-8.82 \mathrm{mM}$ of the dye solution at fixed $\mathrm{FS}$ and $\mathrm{pH}$. Dye removal increases with the increasing dosage of $\mathrm{H}_{2} \mathrm{O}_{2}$ till $2.2 \mathrm{mM}$, after that percentage of removal
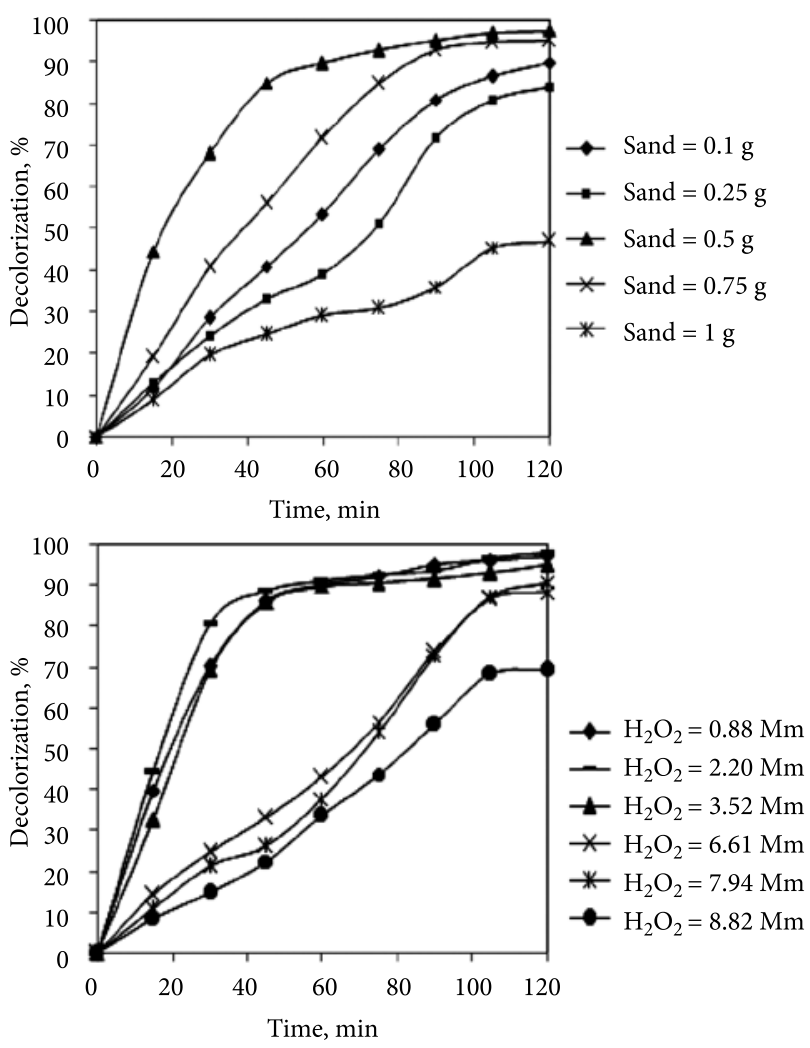

Fig. 5. Percentage degradation and decolourization of RB5 at a) varying concentration of FS b) varying concentration of $\mathrm{H}_{2} \mathrm{O}_{2}$ 


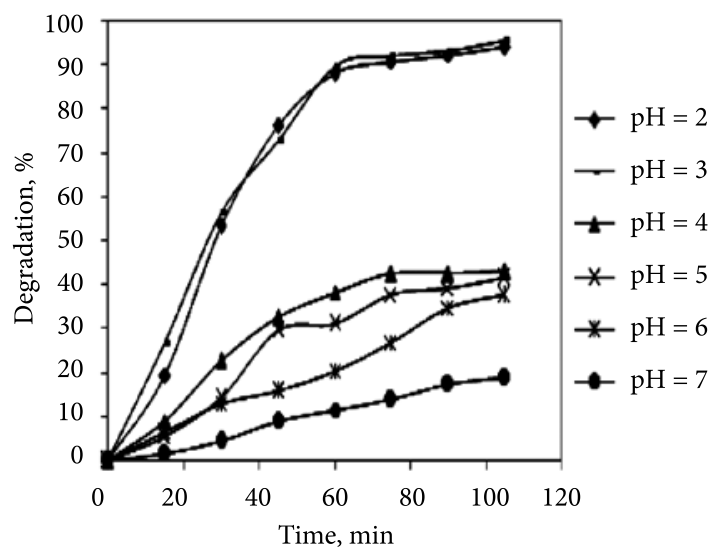

a)

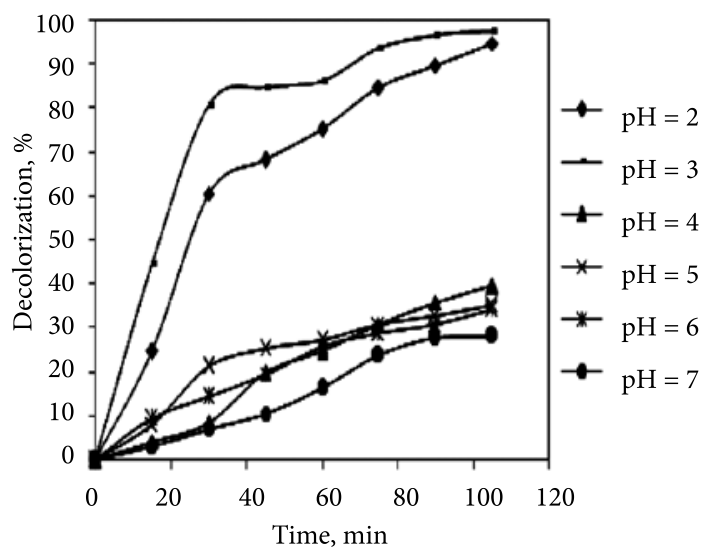

b)

Fig. 6. Percentage a) degradation and b) decolourization of RB5 at different initial $\mathrm{pH}$ of solution

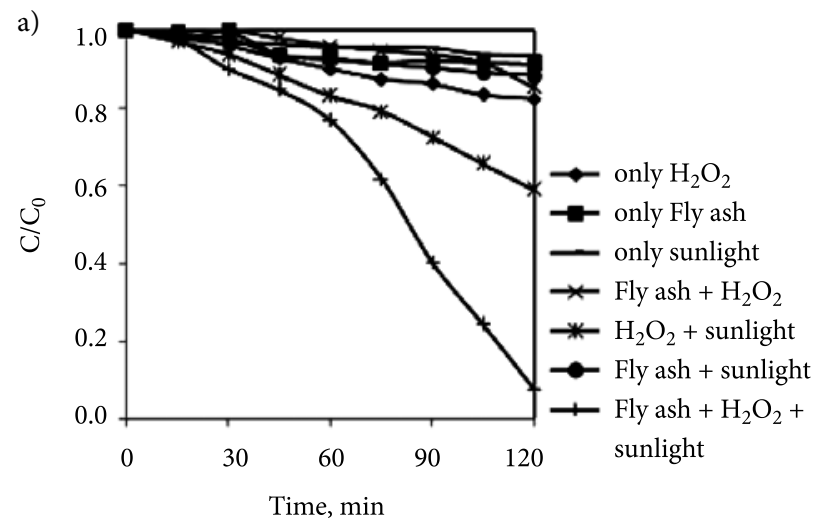

b)

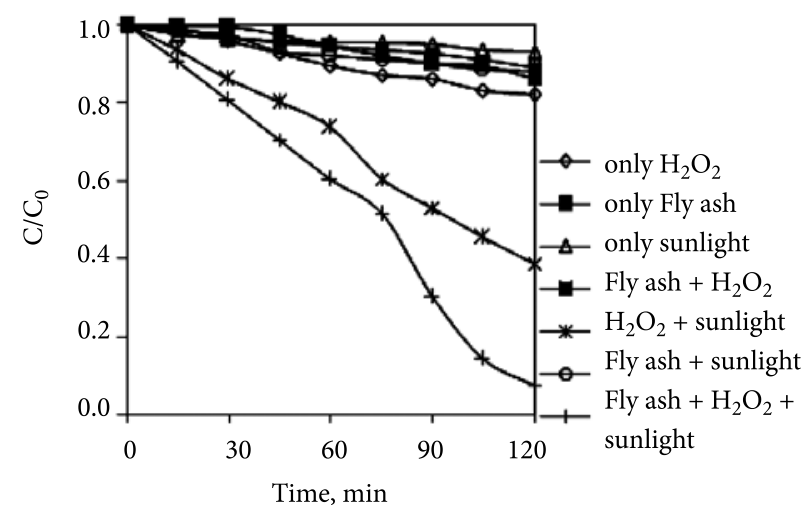

Fig. 7. Preliminary experiments performed under different conditions to evaluate their efficiency towards a) degradation and b) decolourization of RB5 using FA

becomes constant till $6.61 \mathrm{mM}$ and then decreases with the increasing dosage of $\mathrm{H}_{2} \mathrm{O}_{2}$. This decrease is due to the fact of scavenging of $\mathrm{OH}^{\cdot}$ by $\mathrm{H}_{2} \mathrm{O}_{2}$ (Walling 1975; Madhavan et al. 2010), can be expressed by the equation:

$$
\begin{gathered}
\mathrm{OH}+\mathrm{H}_{2} \mathrm{O}_{2} \rightarrow \mathrm{H}_{2} \mathrm{O}+\mathrm{HO}_{2} \cdot \\
\mathrm{HO}_{2}+\mathrm{OH}^{\cdot} \rightarrow \mathrm{H}_{2} \mathrm{O}+\mathrm{O}_{2}
\end{gathered}
$$

Effective degradation (90\%) was achieved within 70 min while decolourization (90\%) of dye solution was achieved within $45 \mathrm{~min}$ of reaction at optimum dose $2.2 \mathrm{mM}$ of $\mathrm{H}_{2} \mathrm{O}_{2}$.

\subsubsection{Effect of $p H$}

The effect of $\mathrm{pH}$ on RB5 degradation and decolourization is shown in Figure 6(a) and 6(b). The pH of the reaction was varied from 2-7. 90\% degradation and decolourization efficiency was achieved at $\mathrm{pH} 3$, for the reaction time of $70 \mathrm{~min}$ and $45 \mathrm{~min}$ respectively. At $\mathrm{pH} 2$, nearly similar results were observed. Further increment in the $\mathrm{pH}$ from 3 leads to reduction in the degradation (18\%) and decolourization (28\%) efficiencies. This behaviour could be explained by the formation of ferric hydroxo complexes during the reaction, which blocks the decomposition of hydrogen peroxide catalyzed by the ferrous irons (Faust, Hoigne 1990; Kitis, Kalpana 2007).

\subsection{Photo-Fenton studies using FA as an iron source}

\subsubsection{Preliminary experiment}

The similar preliminary studies were performed with FA using different conditions as in the case of FS. As shown in Figure 7(a) and (b), the degradation of dye was less than $20 \%$ in the presence of $\mathrm{H}_{2} \mathrm{O}_{2}$, around $15 \%$ in the presence of FA, negligible when exposed to sunlight, $22 \%$ in the presence of $\mathrm{FA}+\mathrm{H}_{2} \mathrm{O}_{2}, 50 \%$ with sunlight $+\mathrm{H}_{2} \mathrm{O}_{2}$, very less in the presence of FA and sunlight, $87 \%$ in the presence of fly ash $+\mathrm{H}_{2} \mathrm{O}_{2}$ and sunlight within $120 \mathrm{~min}$.

\subsubsection{Effect of variation of $F A$}

The effect of FA dose on the degradation of the dye was observed in the range of 0.05-1 gm and shown in Figure 8(a). With the increase of FA dose, degradation and decolourization efficiency increased till certain limit $(0.1 \mathrm{gm})$ after that it was decreased. The optimum amount of FA was $0.1 \mathrm{gm}$ resulting in 92\% degradation in $75 \mathrm{~min}$ and $97 \%$ decolourization in $15 \mathrm{~min}$. At higher 
FA concentration, a relative decrease in degradation and decolourization rates were observed may be due to the adsorption of both $\mathrm{H}_{2} \mathrm{O}_{2}$ and dye molecule on separate particles rather than at the adjacent sides of the same particle and thereby not reacting to each other (Feng

a)

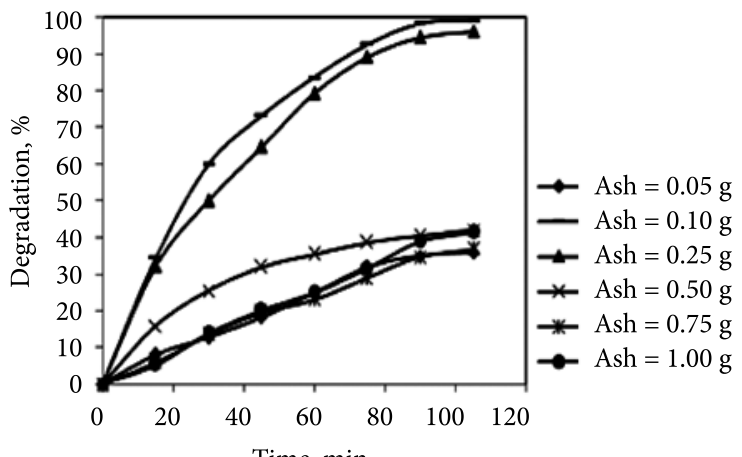

b)

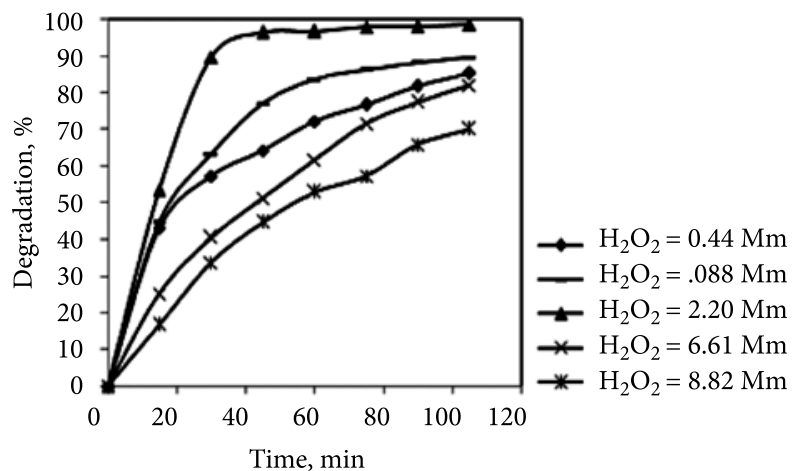

et al. 2003; Catalkaya, Sengul 2005; Tony et al. 2008). This reduction can also be explained due to the fact that, at higher concentration of iron than the optimum, the hydroxyl radical initial formation rate was so high that most of them were consumed by the side reactions

Fig. 8. Percentage degradation and decolourization of RB5 at (a) varying concentration of FA (b) varying concentration of $\mathrm{H}_{2} \mathrm{O}_{2}$

a)
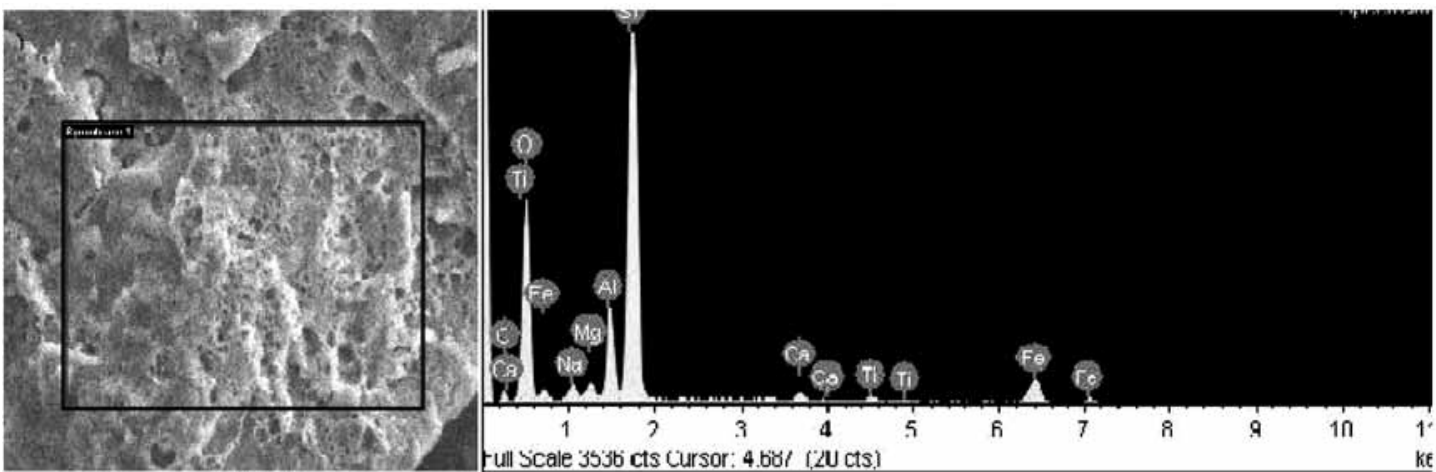

b)
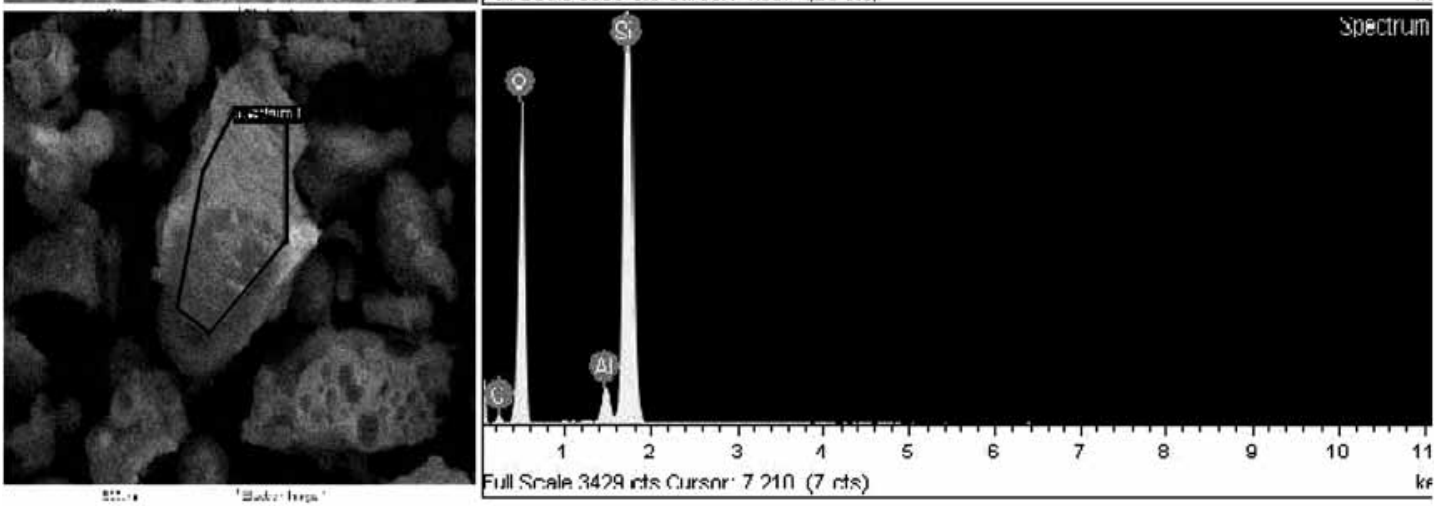

Fig. 9. SEM micrograph and EDS pattern of a) used FA b) used FS, during photo-Fenton treatment of RB5 
before they could be utilized for the mineralization of the compound (Hsueh et al. 2005).

\subsubsection{Effect of $\mathrm{H}_{2} \mathrm{O}_{2}$ concentration}

In the presence of FA, the influence of $\mathrm{H}_{2} \mathrm{O}_{2}$ concentration on the heterogeneous photo- Fenton degradation of the dye was also investigated with different levels of $\mathrm{H}_{2} \mathrm{O}_{2}$ concentration $(0.44,0.88,2.2,6.61$ and $8.82 \mathrm{mM})$ while keeping other operating parameters constant $\left(\mathrm{FA}=0.1 \mathrm{gm}, \mathrm{pH} 3, \mathrm{C}_{0}=100\right.$ $\mathrm{mgL}^{-1}$ ). From the Figure $8(\mathrm{~b})$ it can be illustrated that the effective degradation (90\%) was achieved within $30 \mathrm{~min}$ and decolourization (95\%) within 10 min with optimum dose of
2.2 mM. Further increment in the dosage of $\mathrm{H}_{2} \mathrm{O}_{2}$ leads to decrease in the degradation rates. This reduction may be explained by the so-called hydroxyl radical scavenging effect.

The above study indicated the potential use of FS and FA as an alternative source of iron in photo-Fenton process for the treatment of RB5 dye. Effect of various reaction parameters on the degradation and decolourization efficiency was observed. The SEM- EDS for used FS and FA is shown in Figure 9(a) and (b) and data is shown in Table 3 and 4 . The reduction in the composition of iron and aluminium confirmed their participation in the photo-Fenton reactions.

Table 3. Composition of FS after used in photo-Fenton process

\begin{tabular}{rcccccccccc}
\hline Element & $\mathrm{C} \mathrm{K}$ & $\mathrm{O} \mathrm{K}$ & $\mathrm{Na} \mathrm{K}$ & $\mathrm{Mg} \mathrm{K}$ & $\mathrm{Al} \mathrm{K}$ & $\mathrm{Si} \mathrm{K}$ & $\mathrm{Ca} \mathrm{K}$ & $\mathrm{Ti} \mathrm{K}$ & Fe K & Total \\
\hline Weight \% & 10.87 & 50.50 & 1.42 & 1.06 & 5.49 & 23.37 & 0.64 & 0.51 & 6.15 & 100 \\
\hline Atomic \% & 16.95 & 59.12 & 1.16 & 0.82 & 3.81 & 15.58 & 0.30 & 0.20 & 2.06 & \\
\hline
\end{tabular}

Table 4. Composition of fly ash after used in photo-Fenton process

\begin{tabular}{rccccc}
\hline Element & C K & O K & Al K & Si K & Total \\
\hline Weight \% & 8.33 & 61.12 & 1.54 & 29.02 & 100 \\
\hline Atomic \% & 12.38 & 68.17 & 1.02 & 18.44 & \\
\hline
\end{tabular}

a)

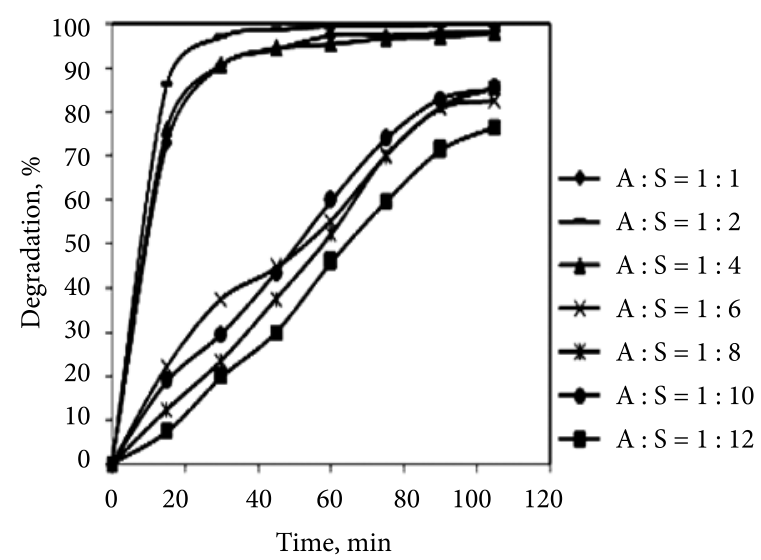

b)

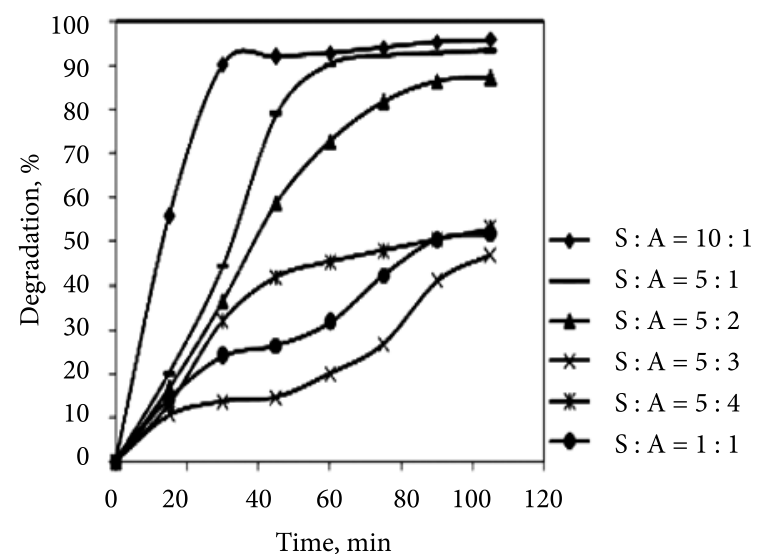

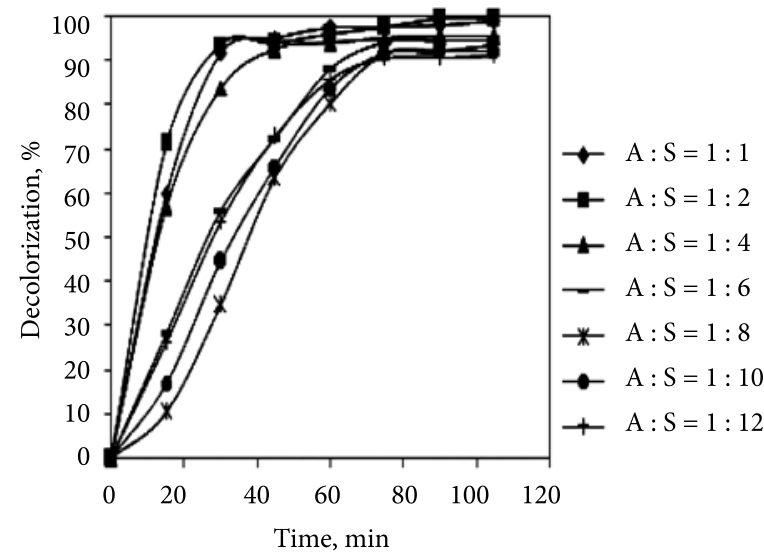

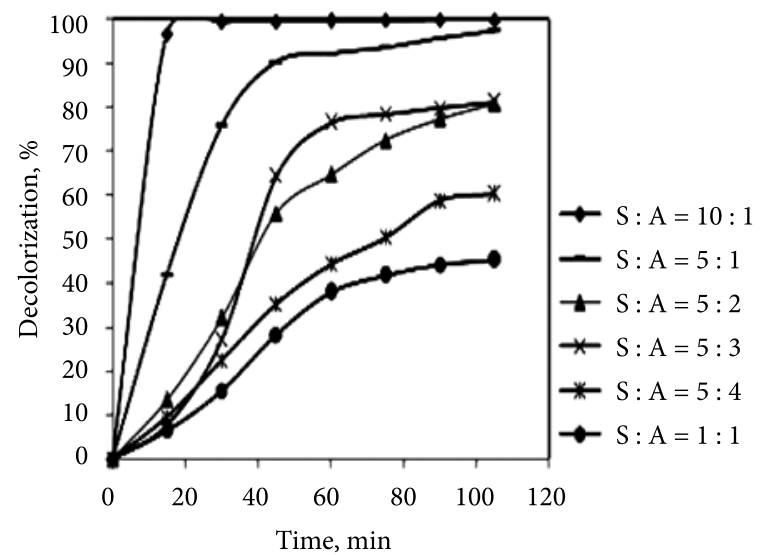

Fig. 10. Percentage degradation and decolourization of RB5 at a) different FA to FS ratio b) different FS to FA ratio 


\subsection{Photo-Fenton studies using mixture of FS and FA as iron source}

\subsubsection{Effect of FS concentration keeping FA constant}

To ascertain the effect of FS in oxidizing RB5, a series of experiments were conducted by varying FS concentration in the ratio of Ash : Sand =1:1, 1:2, 1:4, 1:6, 1:8, 1:10 and $1: 12$. The influence of FS dosage on degradation and decolourization efficiency is illustrated in Figure 10(a). The degradation and decolourization rate of RB5 decreased with increasing amounts of FS. More than 95\% degradation and decolourization rates were achieved with the ratio Ash: Sand = 1:2, where amount of Ash and FS were $0.05 \mathrm{gm}$ and $0.1 \mathrm{gm}$ respectively.

\subsubsection{Effect of FA concentration keeping FS constant}

On similar trend, the effect of varying FA keeping FS and other parameters constant on the degradation and decolourization of RB5 was investigated in the ratio of Sand : Ash $=1: 1,5: 1,5: 2,5: 3,5: 4$ and 10:1 and the results were presented in Figure 10(b). The results indicated that the extent of degradation and decolourization was significantly influenced by the dosage of FA. Decrease in the degradation and decolourization efficiency was observed with increasing amount of fly ash. The optimal ratio value for the degradation (92\%) in $60 \mathrm{~min}$ and decolourization (90\%) in $30 \mathrm{~min}$ for the dye was achieved at Sand : Ash $=10: 1$ where FS and FA were taken $0.5 \mathrm{~g}$ and $0.05 \mathrm{~g}$ respectively.

The above study concluded that the combination of FS and FA gave better results in the terms of degradation and decolourization along with the reduction in the treatment time. For combination of FS and FA, degradation (90\%) after $25 \mathrm{~min}$ and decolourization (97\%) within 10 min was achieved whereas, for the same degradation (90\%) and decolourization (90\%) FS alone took $70 \mathrm{~min}$ and 45 min respectively and FA took $30 \mathrm{~min}$ for $90 \% \mathrm{deg}-$ radation and $15 \mathrm{~min}$ in $93 \%$ decolourization.

Thus, combination gave the better prospects for the use of waste materials like FS and FA to be used as potential iron source in the photo-Fenton process as pre or post treatment options for the degradation of priority pollutants like dyes.

\section{Conclusions}

In this study, attempt has been made for using FS, FA and their combination as heterogeneous catalyst in the photoFenton process for the degradation of RB5.

While using FS as heterogeneous catalyst the maximum degradation and decolourization $95 \%$ and $97 \%$ respectively was achieved and 99\% degradation and decolourization was achieved using FA, thus proposing value addition to waste.
When combination of FS and FA was tried, 99\% degradation and decolourization of RB5 was achieved with different ratios of FA and FS. Thus, presents viable options for using waste materials as source for environmental remediation.

The advantages are high degradation rates (99\%), simple handling, environmental friendly, and low cost (waste as an iron source), which otherwise consumes expenses towards its disposal/land filling.

\section{References}

Arslan, A.; Balcioglu, T.; Tuhkanen. 1999. Oxidative treatment of simulated dye house effluent UV and near-UV lightassisted Fenton's reagent, Chemosphere 39(15): 2767-2783. http://dx.doi.org/10.1016/S0045-6535(99)00211-8

Catalkaya, E. C.; Sengul, F. 2005. Application of Box-Wilson experimental design method for the photo degradation of bakery's yeast industry with $\mathrm{UV} / \mathrm{H}_{2} \mathrm{O}_{2}$ and $\mathrm{UV} / \mathrm{H}_{2} \mathrm{O}_{2} / \mathrm{Fe}(\mathrm{II})$ process, Journal of Hazardous Materials 128(2-3): 201-207. http://dx.doi.org/10.1016/j.jhazmat.2005.07.052

Chaco, J. M.; Leal, M. T.; Sanchez, M.; Bandala, E. R. 2006. Solar photocatalytic degradation of azo-dyes by photo-Fenton process, Dyes and Pigments 69: 44-150.

Chaudhuri, S. K.; Sur, B. 2000. Oxidative decolorization of reactive dye solution using Fly ash as catalyst, Journal of Environmental Engineering 126(7): 583-594. http://dx.doi.org/10.1061/(ASCE)0733-9372(2000)126:7(583)

Chung, K. T.; Stevens, S. E. J.; Cerniglia, C. E. 1992. The reduction of azo dyes by the intestinal microflora, Critical Reviews in Microbiology 18(3): 175-97.

http://dx.doi.org/10.1080/19443994.2013.799440

Chung, K. T.; Stevens, S. E. J. 1993. Degradation of azo dyes by environmental microorganisms and helminths, Environmental Toxicology and Chemistry 54: 435-41.

Djeffal, L.; Abderrahmane, S.; Benzina, M.; Siffert, S.; Fourmentin, S. 2013. Efficiency of natural clay as heterogeneous Fenton and photo-Fenton catalyst for phenol and tyrosol degradation, Desalination and Water Treatment 52(10-12): 2225-2230. http://dx.doi.org/10.1080/19443994.2013.799440

Faust, B. C.; Hoigne, J. 1990. Photolysis of Fe(II)-hydroxyl complexes as sources of $\mathrm{OH}$ radicals in clouds, fog and rain, Atmosphere and Environment 24(1): 79-89. http://dx.doi.org/10.1016/0960-1686(90)90443-Q

Feng, J.; Hu, X.; Yue, P. L.; Zhu, H. Y.; Lu, G. Q. 2003. Discoloration and mineralization of Reactive Red HE-3B by heterogeneous photo-Fenton reaction, Water Research 37(15): 37763784. http://dx.doi.org/10.1016/S0043-1354(03)00268-9

Hsueh, C. L.; Huang, Y. H.; Wang, C. C.; Chen, S. 2005. Degradation of azo dyes using low iron concentration of Fenton and Fenton-like system, Chemosphere 58(10): 1409. http://dx.doi.org/10.1016/j.chemosphere.2004.09.091

Kitis, M.; Kalpana, M. M. 2007. Advanced oxidation of natural organic matter using hydrogen peroxide and iron-coated pumice particles, Chemosphere 68(10): 1846-1853. http://dx.doi.org/10.1016/j.chemosphere.2007.03.027

Lars, B. R.; Mallika, I. 1997. Optimization of Reactive Black 5 dye and Reactive Red 120 dye degradation, Chemosphere 35: 585-597. 
Liao, Q.; Sun, J.; Gao, L. 2009. Degradation of phenol by heterogeneous Fenton reaction using multi-walled carbon nanotube supported $\mathrm{Fe}_{2} \mathrm{O}_{3}$ catalysts, Colloids and Surfaces A: Physicochemical and Engineering Aspects 345(1-3): 95-100. http://dx.doi.org/10.1016/j.colsurfa.2009.04.037

Lucking, F.; Koser, H.; Jank, M.; Ritter, A. 1998. Iron powder, graphite and activated carbon as catalysts for the oxidation of 4-chlorophenol with hydrogen peroxide, Water Research 32(9): 2607-2614.

http://dx.doi.org/10.1016/S0043-1354(98)00016-5

Madhavan, J.; Grieser, F.; Kumar, M. A. 2010. Combined advanced oxidation processes for the synergistic degradation of ibuprofen in aqueous environments, Journal of Hazardous Materials 178(1-3): 202-208. http://dx.doi.org/10.1016/j.jhazmat.2010.01.064

Mahmoodi, N. M.; Arami, M. 2009. Degradation and toxicity reduction of textile waste water using immobilized titania nano photocatalysis, Journal of Photochemistry \& Photobiology B: Biology 94(1): 20-24.

http://dx.doi.org/10.1016/j.jphotobiol.2008.09.004

Mass, R.; Chaudhari, S. 2005. Adsorption and biological decolorization of azo dye Reactive Red-2 in semi continuous anaerobic reactors, Process Biochemistry 40(2): 699-705. http://dx.doi.org/10.1016/j.procbio.2004.01.038

Mecozzi, R.; Palma, L. D.; Pilone, D.; Cerboni, L. 2006. Use of EAF dust as heterogeneous catalyst in Fenton oxidation of PCP contaminated wastewaters, Journal of Hazardous Materials $137(2)$ : 886-892. http://dx.doi.org/10.1016/j.jhazmat.2006.03.002

Pandey, A.; Singh, P.; Iyengar, L. 2007. Bacterial decolorization and degradation of azo dyes, International Biodeterioration \& Biodegradation 59(2): 73-84.

http://dx.doi.org/10.1016/j.ibiod.2006.08.006
Park, H.; Choi, W. 2003. Visible light and Fe(III)-mediated degradation of Acid Orange in the absence of $\mathrm{H}_{2} \mathrm{O}_{2}$, Journal of Photochemistry and Photobiology A: Chemistry 159(3): 241-7. http://dx.doi.org/10.1016/S1010-6030(03)00141-2

Sun, J. H.; Sun, S. P.; Wang, G. L.; Qiao, L. P. 2008. Degradation of azo dye Amido black 10B in aqueous solution by Fenton oxidation process, Dyes and Pigments 74(3): 647-652. http://dx.doi.org/10.1016/j.dyepig.2006.04.006

Tanaka, K.; Padermpole, K.; Hisanaga, T. 2000. Photocatalytic degradation of commercial azo dyes, Water Research 34(1): 327-333. http://dx.doi.org/10.1016/S0043-1354(99)00093-7

Tony, M. A.; Zhao, Y. Q.; Fu, J. F.; Tayeb, A. M. 2008. Conditioning of aluminium-based water treatment sludge with Fenton's reagent: effectiveness and optimizing study to improve dewaterability, Chemosphere 72(4): 673-677.

http://dx.doi.org/10.1016/j.chemosphere.2008.03.032

Toor, A. P.; Verma, A.; Singh, V.; Jotshi, C. K.; Bajpai, P. K. 2006. Photocatalytic degradation of Direct Yellow 12 dye using $\mathrm{UV} / \mathrm{TiO}_{2}$ in a shallow pond slurry reactor, Dyes and Pigments 68(1): 53-60. http://dx.doi.org/10.1016/j.dyepig.2004.12.009

Walling, C. H. 1975. Fenton's reagent revisited, Accounts of Chemical Research 8(4): 125-131.

http://dx.doi.org/10.1021/ar50088a003

Wang, K. S.; Chen, H. Y.; Huang, L. C.; Su, Y. C.; Chang, S. H. 2008. Degradation of Reactive Black 5 using combined electrochemical degradation- solar- light/immobilized $\mathrm{TiO}_{2}$ film process and toxicity evaluation, Chemosphere 72(2): 299-305. http://dx.doi.org/10.1016/j.chemosphere.2008.02.012

Yoshida, Y.; Ogata, S.; Nakamatsu, S.; Shimamune, T.; Kikawa, K.; Inoue, H. 1999. Decolorization of azo dye using atomic hydrogen permeating through a Pt-modified palladized Pd sheet electrode, Electrochimica Acta 45(3): 409-414. http://dx.doi.org/10.1016/S0013-4686(99)00277-7

Anoop VERMA, Dr, is Assistant Professor in School of Energy and Environment, Thapar University, Patiala, Punjab, India. $\mathrm{PhD}$ in Environmental Engineering. Basic research interests are in the field of advanced oxidation processes, photoFenton treatment using alternate iron sources, fixed-bed photocatalysis etc. Verma and his team has published more than 18 papers in various international journals and presented more than 25 papers in international and national conferences.

Amrit Pal TOOR, Dr Professor in Dr. SSB University Institute of Chemical Engineering and Technology, Panjab University, Chandigarh. She is having more than 25 years of experience in the field of chemical engineering, waste treatment and published more than 30 papers in SCI journals. Presently, she is working of production of bio-diesel from non-edible plants with process kinetics. Research interests basically include advanced oxidation processes, bio-diesel production, etc.

Himadari RAJPUT, M. Tech. student, research area: Advanced Oxidation Processes for the removal of persistent pollutants from wastewater. A participant of four conferences.

Manpreet KAUR, M. Tech. student, research area: Advanced Oxidation Processes for the removal of persistent pollutants from wastewater. A participant of four conferences.

Taranjeet KAUR, PhD student perusing her degree in the field of pesticides degradation using Advanced Oxidation Processes. She has published few papers on pesticide degradation using photocatalysis. Research interests: field of photocatalysis with doped catalyst. 